\title{
THE UNCLAIMED INHERITANCE ISSUES: A SOLUTION USING BLOCKCHAIN TECHNOLOGY
}

\author{
"Wan Nur Izzah Wan Muhamad Fokri, Engku Muhammad Tajuddin Engku Ali,Nadhirah Nordin, \\ Wan Mohd Yusof Wan Chik, Sumayyah Abdul Aziz,Ahmad Jazlan Mat Jusoh \\ Universiti Sultan Zainal Abidin, Malaysia \\ *Corresponding Author: izzahfokri.we@gmail.com
}

\begin{abstract}
Unclaimed inheritance retards the economy as well as the continuity of life, especially for beneficiaries who are less capable. Recorded cases of unclaimed inheritance have seen a yearly rise, and this also has an effect on the Malaysian economy, mainly due to the failure to distribute immoveable property, such as the failure to transfer the ownership of land and houses. This causes the land to become abandoned and underdeveloped. Hence, various measures are needed to solve the unclaimed inheritance problem and contemporary technology should be fully utilised to overcome this problem. This study intended to explore the benefits of blockchain technology for solving the unclaimed inheritance problem. Blockchain technology is a database system that replaces the traditional system with various advantageous, which makes organisational management more effective and systematic. This technology supports the implementation of a smart contract, which acts as a medium for managing inheritance distribution to ensure no beneficiaries is left out and receives the rightful share. A smart contract is an agreement in digital form that uses a certain protocol and only applies to the relevant parties. This study applied the qualitative approach and a descriptive research design. Data collected through document analysis and interview methods. Data from the document analysis method involved primary and secondary sources, while the semi-structured interview method was used for field studies. Findings showed that the blockchain technology is an appropriate solution for solving unclaimed inheritance problems. However, a blockchain based smart contract requires the cooperation between the party authorised to distribute inheritance property and the banks as well as other government agencies in order to ensure that the inheritance distribution process is carried out smoothly. This study benefits the authorities in charge of inheritance management as well as act as a guide for future researchers. This study offers a theoretical solution for solving the distribution of unclaimed inheritance by using blockchain based smart contract.
\end{abstract}

Keyword:

Management, inheritance property, blockchain, smart contract, technology.

Article Received: 18 October 2020, Revised: 3 November 2020, Accepted: 24 December 2020

\section{INTRODUCTION}

Malaysia has authorised three institutions to manage the distribution of inheritance property, namely Amanah Raya Berhad (ARB), the Small Estates Unit in the Department of the Director General of Lands and Mines (JKPTG) and the High Court. The jurisdiction of each institution is subject to the type and total amount of the property. However, not all of society is aware of the procedures regarding the distribution of inheritance property as well as which authority should be approached when a death occurs (Ahmad et al. 2018). This leads to the public referring their case to unrelated authorities, such as banks or Takaful agents, which creates the perception that managing inheritance property distribution is a tedious and complicated affair. Some decide to forget the matter and not make any claim on the inheritance property, which then stifles the economy as well as impede the continuity of daily life, especially beneficiaries who are financially unstable. The amount of unclaimed inheritance property increases yearly (Aziz, 2016). Hence, a suggestion for solving the unclaimed inheritance property problem must be made to those involved and contemporary technology must be maximally optimised to arrest the increase in unclaimed inheritance property cases. Blockchain technology is a type of database technology that can replace the traditional method used for solving unclaimed inheritance property cases (Shariffuddin, 2020). Blockchain comprises 
blocks that cannot be changed or hacked by anybody and has many networks where new data are kept and revised in each network. Thus, if anyone wishes to change data in any of the blocks, they have to change data in each network found in the blockchain (Mohanta et al., 2018; Karamitsos, 2018). Blockchain technology supports the building of a smart contract, which involves an agreement in digital form that uses a certain protocol between the relevant parties (Mukhopadhyay, 2018). A smart contract functions in when an event and its implication occurs according to a specific logic code that has been developed (Mohanta et al., 2018; Karamitsos, 2018; Mukhopadhyay, 2018). This will facilitate the automatic transfer of ownership of inherited property to the beneficiaries after a death occurs.

\section{UNCLAIMED INHERITANCE PROPERTY}

Islam has established a method for distributing inheritance property according to specific shares or apportionments to the rightful heir(s), as mentioned in the al-Quran and hadith. However, not all Muslims are well-versed with these legal provisions and they usually give three main reasons as to why they are not concerned about laying claim to their share of the inheritance property. Firstly, death rarely occurs in their family. Secondly, not all of them who die leave behind property and thirdly, distribution of inheritance property involves mathematical calculations that many dislike (Syarifuddin, 2005; Anon, 2005).

Attitudes and ethical practices of some of the heirs also affect the administration of inheritance property, such as procrastination, infighting amongst heirs, concealing the list of heirs apparent and breach of trust. Procrastination and infighting amongst heirs will lead to an overlap in deaths of succeeding generations, which will complicate the distribution of the inheritance property and take a long time to settle (Sulong, 2011; Ahmad \& Laludin, 2010; Wajis et al., 2018).

According to the Small Estate Section in JKPTG, inheritance property applications are made six months from the date of demise, although there are many that are made many years later. Some heirs boycott the property distribution hearing sessions and do not cooperate throughout the sessions. Hence, it is not surprising that during big scale land acquisition projects there are between $15 \%$ to $35 \%$ of land owners who have already died and this percentage is much higher for rural agricultural land and lands that have been registered for a long time (Sulong, 2011).

Utusan Malaysia (2 May 2009) reported that RM31 million belonging to those who have died is yet to be claimed by their heirs from Amanah Raya Berhad. This huge amount is categorised as "Inheritance Property Waiting to be Claimed". This "Inheritance Property Waiting to be Claimed" refers to inheritance property that is yet to be administered or distributed to the heirs apparent due to certain reasons. Alina Hashim, Head of Operations at the Amanah Raya Group, stated that inheritance property administered by ARB amounted to RM696 million, and when combined with the "Inheritance Property Waiting to be Claimed", it reaches a total of RM727 million. The inheritance property amounting to RM696 million comprises movable (RM146 million) and unmovable (RM550 million) property (Rahim, 2009).

Omar (2016) stated in the Berita Harian that there are RM60 billion worth of unclaimed assets comprising land and buildings as well as frozen property. In 2006 there were 1 million frozen inheritance property claims valued at RM38 billion, which increased to RM40 billion in 2009. One of the main reasons why properties are not claimed is the lack of awareness of property management among members of society, which inadvertently leads to a lack of planning needed to solve the problem. Good planning requires knowledge about relevant procedures and processes. 
An increase in the total amount of unclaimed inheritance property indicates that the relevant authorities should seek solutions for this problem. Property that rightly belongs to the heirs and can enhance their lives cannot be benefitted when it is still frozen without any action taken by the heirs apparent. Therefore, it is appropriate that contemporary technology is maximally optimised as a solution to solve the unclaimed inheritance property issue.

\section{BLOCKCHAIN TECHNOLOGY}

The blockchain technology concept was adduced by Haber dan Stornetta (1991) in order to maintain the timestamp, which is a coded sequence of characters or information that helps to determine when an event will occur. The timestamp usually records the time and date pertinent to a transaction, message, or data in order to differentiate it from other information by using the cryptography system. Timestamp is used to prevent repetitions based on the terminal protocol. The cryptography system is a method for manipulating data content in a message to ensure the confidentiality and authenticity of the message by producing a hash from the stored data (Karamitsos et al., 2018). Hash is obtained from mathematical operations that consider the value of random-sized bytes as input and produce a summarised byte value with a fixed size as the output. Haber and Stornetta (1991) stated that the increasing use of texts, audio and video in digital form and the convenience of altering the document has given rise to a new problem, which is certifying when the document was first produced or when it was last altered. There are two aspects that must be present in the solution for the problem, namely the timestamp written on the document should be an actual byte without making assumptions about the physical medium where the document was recorded and second, the date and time on the timestamp cannot be falsified or doctored. Among the suggestions adduced is the use of hashing, which is a process of obtaining output in summarised byte value on the actual document and a digital signature as well as distributing information to clients without any monitoring by the Time-Stamping Services (TSS). The two fundamentals of blockchain technology are the distribution system and cryptography. When two clients wish to interact in a normal system, they need to apply to the server, which acts as an intermediary. The distribution system acts as the basis for the blockchain technology to eliminate the role of the intermediary (Karamitsos et al., 2018) and each node can possibly be a client or server, which makes it difficult to differentiate between other nodes (Mukhopadhyay, 2018).

Blockchain technology was first implemented, based on the concept by Satoshi Nakamoto, to produce the first crypto currency called Bitcoin. Bitcoin, a form of electronic cash, is a peer-to-peer transaction that allows online transactions directly with another party without any financial institution acting as an intermediary. A framework was built to assist the peer-to-peer transaction that allows online transactions directly with another party without going through any financial network by using the Proof of Work protocol to record all transactions (Nakamoto, tt; Karamitsos et al., 2018; Nawang \& Azmi, 2020; Rutskiy et al., 2020). Each transaction is certified by the node that has joined the network through the Proof of Work protocol, which is a mathematical algorithm solution. The algorithm solution is then certified by all the nodes in the network and record of the new transaction is reviewed and stored by all nodes (Karamitsos et al., 2018; Mohanta et al., 2018; Rutskiy et al., 2020). None of the nodes will know the identity of those involved in the transaction and the identity is replaced with a address wallet, which is a hash of the public key that uses cryptography (Eskandari et al., 2018). A transaction is impossible to perform securely in virtual reality without the use of cryptography (Z'aba, $t \mathrm{tt})$. 
The blockchain evolution comes in three phases. In the first phase, blockchain technology involves cash money, such as transfer of currency, remittance of money and the digital payment system. The second phase concerns the implementation of a contract involving a wider economic market and range of financial instruments compared to simple cash transactions, such as shares, bonds, future trading, mortgages, loans as well as intellectual property, using blockchain technology. The third phase involves blockchain technology, other than for currency, financial and market uses. The use of blockchain technology in the third phase involves the government, health, science, culture, and arts fields (Karamitsos et al., 2018; Mukhopadhyay, 2018; Azizam et al., 2020). Blockchain technology has been used in various situations throughout the three phases since the first implementation of blockchain technology, which was for creating the Bitcoin. Some crypto currencies such as Ethereum and Ripple also support the building of a smart contract in its blockchain.

\section{SMART CONTRACT}

In the analogue era and before the emergence of blockchain technology and the Internet, mechanical equipment, such as the vending machine, was created to implement the smart contract. The consumer can choose the product after the required payment is made in the stipulated currency. After the code has been identified and confirmed, the chosen product with emerge from the vending machine; however, the transaction will fail if no payment is made or the consumer takes a very long time to choose the product according to the payment made. The code will not certify a transaction if the amount put into the machine is not equivalent to the amount stipulated and the chosen product will not emerge from the vending machine. The vending machine is one example of a smart contract that has existed before blockchain technology and the Internet came about (Mukhopadhyay, 2018).

Nick Szabo introduced the term smart contract in the 1990s (Mukhopadhyay, 2018; Mohanta et al., 2018, Karamitsos et al., 2018) and formally defined it as an agreement in digital form, which includes the protocols used by parties involved in the implementation of the agreement. According to the definition, the smart contract contains four elements, which are an agreement, in digital form, implemented by using certain protocols and only involves parties to the agreement (Mukhopadhyay, 2018). An agreement is usually a commercial agreement, such as establishing the profit ratio when the company registers profit and adjusting the ratio to recover losses when the company registers losses. The second element is the digital form, which is stated in a coded line and can be read by anyone, such as conditions set by a certain software and the product would be changed into two main codes, namely a collection of digits from 1 to 0 . A protocol is a set of regulations that guides the parties involved to process data related to the smart contract. A set of instructions is conveyed through technology, implemented by using computer algorithms and operates based on instructions that allows an action, such as release of payments when certain conditions or circumstances have been fulfilled. A smart contract is between the parties involved and the contract is coded and cannot be cancelled. Hence, the contract cannot be enforced if it does not fulfil the stipulated conditions (Mukhopadhyay, 2018).

Deloitte, an auditing firm that has collaborated with the Board of Advisers to the Digital Chamber of Commerce, had adduced six anatomies related to the smart contract, as explained in 1. 
Figure 1: Anatomy of the smart contract structure

Source: Mukhopadhyay, 2018

Introduction to the Agreement
- Identifying opportunities for colloborating with the parties involved.
- Agreements that have the potential for a transfer of rights or change in assets.
Establishing Conditions or Clauses
- Events that cause a situation, such as a natural catastrophe.
- Time when a certain event occurs, such as a death or anniversary.
Coding the Business Logic
- Coding will occur automatically when several conditions in the contract are
fulfilled.
Digital Signature
- Provisions for a safe confirmation and the confirmation of a message between
parties in a smart contract.
Implementation Process
- When there is a consensus on the confirmation, the smart contract is carried out
and the results are recorded for auditing purposes.
Revising the Network
- After the smart contract is implemented, each node involved in the network will
revise the present conditions in the smart contract.

Figure 1 shows six anatomies for structuring a smart contract. An activated smart contract cannot be prevented from being implemented. Certain circumstances or conditions will have implications on the smart contract based on the logic coding that has been encoded before creating the contract (Mukhopadhyay, 2018; Mohanta et al., 2018, Karamitsos et al., 2018). Developing a smart contract based on the digital currency blockchain would incur a charge on the digital currency, albeit at a low rate. The charge is calculated based on power and data capacity used for developing an application or contract (Ethereum Community, 2017).

Therefore, if a smart contract is developed in the Ethereum blockchain, then the parties to the contract need to pay a gas fee as a charge for implementing the application there. All transaction chargers related to the Ethereum blockchain must be paid using Ether. However, if the user does not want to be obligated to any other currency, then the user must develop his/her own blockchain technology (Dannen, 2017). Gas is the unit of work used to determine the transaction chargers for an operation in the Ethereum blockchain. The cost of the gas is paid in Ether units, which is known as gwei and is worth $10^{-9}$ of the Ether (Crypto Casey, 2020). All transactions occurring in the Ethereum blockchain will also be charged in the form of gwei, which are not only limited to charges for implementing the smart contract, but also for all peer-to-peer transactions in the Ethereum network (Azzuhri, 2020).

\section{BLOCKCHAIN TECHNOLOGY AS A} SOLUTION FOR UNCLAIMED

\section{INHERITANCE PROPERTY}

A yearly increase in the number of recorded unclaimed inheritance property cases has a direct effect on the heirs apparent and the Malaysian economy. Hence, blockchain technology can be an initiative to arrest the growing number of unclaimed inheritance property cases by implementing this technology from the very start, which begins from the inheritance property distribution process right after a death occurs. The implementation of this technology requires the use of a database system that is similar across all the interested parties involved, such as the National Registration Department (JPN), High Courts, Land Office, Land Transport Department (JPJ) and other financial institutions.

Each death must be certified by an attending agency, such as the hospital, the police 
(PDRM) or the Kuala Lumpur City Hall (DBKL). After the agency issues a Death Registration or a Burial Permit, the heir is required to send the document to the National Registration Department (JPN) in order to obtain the death certificate and for the death to be recorded in the department's IJPN (JPN, tt).

After obtaining the death certificate only then can the heir forward claims for distributing the inheritance property at the Inheritance Property Distribution Unit in JKPTG, ARB or the High Court by adducing documents pertaining to movable and unmovable property. Thus, if the deceased had left behind unmovable property (e.g. land), the heir(s) is required to adduce a copy of the land title certified by the Land Office or an Official Search Certificate, which shows that the deceased owns the property or a sales and purchase agreement for a house that does not have a land title, copy of the quit rent receipt for a house or building and unissued Strata title and quit rent receipts, if any. Heirs are also required to adduce latest documents related to movable property, such as copies of share certificates, saving account book, vehicle registration, KWSP certificate etc. These three institutions will take four months to one year to settle the administration and claim of inheritance property processes (JKPTG, $\mathrm{tt}$; ARB, $\mathrm{tt}$ ). The inheritance property application process is explained in Figure

Figure 2: The Property Inheritance Claim Process

\begin{tabular}{|c|}
\hline Hospital - To obtain a confirmation of the death \\
\hline PDNM/DBKL - To obtain the Burial Permit \\
\hline Financial Institution - To obtain documents concerning the movable property \\
\hline Land Office - To obtain documents concerning inmovable property, if any \\
\hline High Court/ JKPTG/ ARB - Apply for inheritance property claims \\
\hline In 4 months to 1 year, the heir(s) will receive a Inheritance Property Distribution Order \\
\hline \\
\hline Financial Institution- To claim the share that has been distributed \\
\hline Land Office - To obtain a new land title according to the distributed share \\
\hline
\end{tabular}

There are nine steps an heir should take to obtain his/her share of the property left behind by the deceased according to the inheritance property distribution claim process in Malaysia. Hence, if blockchain technology and the smart contract are fully utilised in the inheritance property distribution process, then the process would be much shorter and systematic. Figure 3 shows the smart contract related to the inheritance property distribution system.

Figure 3: A smart contract based on the inheritance distribution system. 


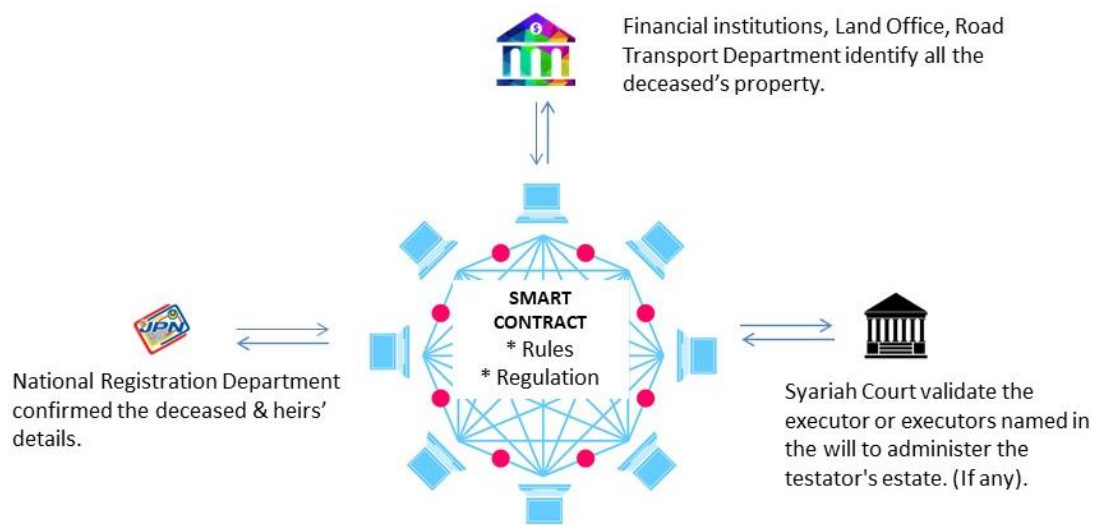

Smart contract is verified by the network. If network agree, then inheritance distribution in the form of savings and shares will be transferred directly to all heirs' account. The ownership of land and vehicle transferred to certain heirs according to the regulation. All data added and recorded in blockchain.

Figure 3 shows the inheritance property distribution system that uses a smart contract. The heir apparent only needs to report the death to the JPN by adducing the Death Registration or Burial Permit. Then, the JPN will certify the particulars of the deceased and the heir. Whereas the High Court will certify the name(s) mentioned in the will left by the deceased, if there is any. The agencies involved should store data in the blockchain before developing the smart contract as an inheritance property distribution medium. For example, if JPN certifies that the deceased is a Muslim, then the distribution of the inheritance property will be conducted according to Islamic law, which is Faraid and the will is applicable as long as it is not more than $1 / 3$ of the total assets. A smart contract will be certified by the network in the blockchain and after obtaining the certification from the network, then the total amount of property will be directly distributed among the heirs (or heir) according to the law. Property in the form of shares and money will be channelled directly into the heir's account, whereas ownership of vehicles and land will be transferred to the new owner. The latest data will be revised and kept in the blockchain.

The use of a smart contract can replace the traditional method of administrating inheritance property and its implementation can reduce costs and eliminate the involvement of middlemen or intermediaries who assist in the inheritance property distribution process. Besides that, the process takes a shorter time compared to the traditional method. Therefore, developing a smart contract to be used in the inheritance property distribution system requires the collaboration of all agencies involved. These agencies need to store and share data in the blockchain technology before gaining access to implement the system based on a smart contract.

\section{CONCLUSION}

The yearly increase in the number of unclaimed inheritance property cases influences the live of the heir(s) and the Malaysian economy. Hence, this problem cannot be taken lightly, and contemporary technology must be benefitted for the sake of society and the country. A smart contract supported by blockchain technology can be the exact solution for overcoming this problem beginning with the distribution of the inheritance property. The inheritance property distribution system based on the smart contract can reduce costs and eliminate the involvement of middlemen or intermediaries as well as speed up the distribution of inheritance property to its rightful heirs. However, this implementation needs the collaboration of all participating agencies using blockchain technology, such as JPN, JPJ, financial institutions, the Land Office and High Court as well as a common database system. 
This research was funded by the Ministry of Higher Education Malaysia under the research grant fund, namely the Fundamental Research Grant Scheme

(FRGS)

FRGS/1/2018/SS08/UNISZA/02/1 entitled

'Shariah Guidelines for Digital Currency Transaction'.

\section{REFERENCES}

[1] Ahmad, MY. \& Laludin, H. (2010). Pengurusan Harta Pusaka: Permasalahan Sikap Masyarakat Islam di Malaysia dan Penyelesaiannya Menurut Perspektif Islam. Syariah Law Report. Vol 4. pp 30-54.

[2] Ahmad, MY. Mohamad MN. Muda, MZ. Jamsari, EA. Hasan, WZW. \& Kashim, MIAM. (2018). Confronting The Problem of Managing Unclaimed Inheritance Property of Muslims in Malaysia. International Journal of Civil Engineering and Technology. Vol. 9. Issue 4. April 2018. pp 1459-1466.

[3] Anon. (2005, 30 September). RM471 Juta Harta Pusaka Masih Gagal Diagih. Utusan Malaysia.

[4] ARB. (tt). Soalan Lazim Pentadbiran Pusaka. Retrived from https://www.amanahraya.my/ms/pentadbira n-pusaka/soalan-lazim-pusaka/.

[5] Aziz, Ilah Hafiz. (2016, 29 March). RM60b harta umat Islam tidak dituntut. Berita Harian. Retrieved from https://www.bharian.com.my/node/138450.

[6] Azizam, SA. Saany, SIA. Noh, EAM. Hashim, NAN. Waqas, M. El-Ebiary, YAB. Blockchain As A Secure and Decentralized Communication Tool For Future Sustainable Development. PalArch's Journal of Archaeology of Egypt / Egyptology, Vol 17. No. 9. pp 942 - 953.

[7] Azzuhri, Saaidal Razalli. (2020, 31 January). Personal interview.

[8] Crypto Casey. (2020, 29 Februari). Ethereum 2020 Explained: What is
Ethereum \& How it Works (Ultimate Beginner's Guide). Retrieved from https://www.youtube.com/watch?v=DhoRt GCp4JI.

[9] Dannen, C. (2017). Introducing Ethereum and Solidity: Foundations of Cryptocurrency and Blockchain

Programming for Beginners. Springer Science+Business Media New York: USA.

[10] Dewan Bahasa Pustaka. (tt). Carian Umum. Retrieved from prpm.dbp.gov.my.

[11] Ethereum Community. (2017). Ethereum Homestead Documentation - Release 0.1 (March 01, 2017)

[12] Eskandari, S. Barrera, D. Stobert, E. \& Clark, J. (2018). A First Look at the Usability of Bitcoin Key Management.

[13] Haber, S. \& Stornetta, WS. (1991). How To Time-Stamp a Digital Document. Journal of Cryptology. 1991.3. pp 99-111.

[14] JKPTG. (tt). Pembahagian Harta Pusaka Kecil. Retrived from https://www.jkptg.gov.my/index.php/my/pe rmohonan-pusaka.

[15] JPN. (tt). Mendaftar Kematian Biasa (Semenanjung). Retrieved from https://www.jpn.gov.my/maklumatkematian/mendaftar-kematian-biasa/.

[16] Karamitsos, I. Papadaki, M. Al-Balghuti, NB. (2018) Design of the Blockchain Smart Contract: A Use Case for Real Estate. Journal of Informative Security. 2018. 9. pp 177-190.

[17] Mohanta, BK. Panda, SS. \& Jena D. (2018). An Overview of Smart Contract and Use cases in Blockchain Technology. 9th ICCCNT 2018. July 10-12 2018. Bengluru, India.

[18] Mukhopadhyay, M. (2018). Ethereum Smart Contract Development. Birmingham: Packt Publishing Ltd.

[19] Nakamoto, S. (tt). Bitcoin: A Peer-to-Peer Electronic Cash System. 
[20] Nawang, NI. \& Azmi, IMAG. (2020). Cryptocurrency: An Insight Into The Malaysian Regulatory Approach. Hamdard Islamicus, Vol. 43. No. S.2. pp 262-271.

[21] Omar, Ismail. (2016, 12 May). Manfaat aset hartanah tidak dituntut. Berita Harian. Retrieved from https://www.bharian.com.my/node/152784.

[22] Rahim, Tarmizi Abdul. (2009, 2 May). RM31J Harta Pusaka Masih Tidak Dituntut. Utusan Malaysia.

[23] Rutskiy, V. Javed, S. Azizam, SH. Zhigalov, NCK. Kuzmich, R. Pupkov, A. Tsarev, R. (2020). The Price Determinants of Bitcoin as a New Digital Form of Money. Proceedings of the Computational Methods in Systems and Software. CoMeSySo 2020: Software Engineering Perspectives in Intelligent Systems. pp 784792.

[24] Shariffuddin, Aliff. (2020, 13 March). Focus Group Discussion.

[25] Sulong, Jasni. (2011). Pembaharuan Undang-undang Pentadbiran Pusaka Islam. Pulau Pinang: Penerbit Universiti Sains Malaysia.

[26] Syarifuddin, Amir. (2005). Hukum Perwarisan Islam. Jakarta: Prenada Media.

[27] Wajis, NRN. Mutalib, LA. Rahman, AA. Sahid, MM. Saleh, NSSN, Rusli, MHM. Ali, MM. Rab, MAA. Gunardi, S. Tagoranao, MS. Saleh, MAM. Hanafo, LHH. \& Ahmad, AS. (2018) Harta Tidak Dituntut: Punca dan Kaedah Penyelesaiannya. Malaysian Journal of Syariah and Law. Vol 7. June 2018. pp 129-141.

[28] Z'aba, Muhammad Reza. (tt). Kriptografi: Sejarah dan Asal Usulnya. Retrieved from https://coin.my/blockchain/kriptografisejarah-dan-asal-usulnya/. 